\title{
DATA SECURITY USING RJB32 METHOD
}

\author{
R. Jaichandran ${ }^{1}$, Dr. Avinash Sharma ${ }^{2 * *}$, Nethaji $A^{3}$, Nithish Kumar K.N ${ }^{4}$, Guru \\ Vignesh $\mathrm{M}^{5}$, and Suhail Jalal ${ }^{6}$ \\ 1,3,4,5,6 Department Of Computer Science And Engineering \\ Aarupadai Veedu Institute Of Technology \\ Vinayaka Mission'S Research Foundation \\ Paiyanoor-603 104, Tamil Nadu, India. \\ ${ }^{1}$ rjaichandran@avit.ac.in, ${ }^{3}$ mukesh.ajay99@gmail.com, ${ }^{4} 98$ nitish@gmail.com \\ ${ }^{5}$ guruvigneshvijay@gmail.com, ${ }^{6}$ asifjalal1998@gmail.com
}

${ }^{2}$ Professor, CSE Department, M.M. Deemed to be University, Mullana, Haryana, India, 133207 asharma@mmumullana.org

Corresponding Author: Dr. Avinash Sharma ${ }^{2 * *}$

Abstract. The present world is data world; without this data cannot survive in present stage. This data produced more from social media; this media data is public data; This public data not have good security; so to overcome this issue we apply the Salsa method. This method easily hack the data from the hackers. RBJ32 method has 5 steps. 1. Applying the key and multiply that key; 2. To apply the prime number in the $S^{2}$ and $T^{2}$; 3. To calculate the EA1 and EA2; 4. To swap the EA1 and EA2 in matrix EnA; 5. Apply the column operations. The proposed method provides good security while comparing with Salsa method.

Key words: RJB32, Prime, Salsa, Encryption, Decryption.

\section{INTRODUCTION}

The present world is data world; without this data cannot survive in present stage. This data produced more from social media; this media data is public data; This public data not have good security; so to overcome this issue we apply the Salsa method. This method easily hack the data from the hackers. The additional rotations XOR for ChaCha is fault attack [1]. This author is used new hash concept for key guessing and halting condition [2]. Author was introduced the bricklayer attack for analysis of ChaCha [3]. They mainly focus the security for Double A [4]. They made new design for secure fast and flexible algorithm [5]. SRB18 method used to provide security for data [6]. SRB21 method used to provide security for data [7]. CBB21 method

TABLE 1. Applying prime numbers in ES and ET

\begin{tabular}{|l|l|l|l|c|c|}
\hline $\mathrm{S}$ & $\mathrm{T}$ & $S^{2}$ & $T^{2}$ & Equation(2) and (6) & Equation(3) and (7) \\
\hline $\mathbf{3}$ & $\mathbf{1}$ & 9 & $\mathbf{1}$ & 8 & 10 \\
\hline $\mathbf{5}$ & $\mathbf{1}$ & 25 & $\mathbf{1}$ & 24 & 26 \\
\hline
\end{tabular}




\begin{tabular}{|l|l|l|l|l|l|}
\hline 7 & 3 & 49 & 9 & 40 & 58 \\
\hline 9 & 3 & 81 & 9 & 72 & 90 \\
\hline
\end{tabular}

used to provide security for data [8]. CBB22 method used to provide security for data [9]. To overcome this problem introduced the novel method RJB32( Rajaprakash Jaichandran and Bagath Basha) 32.

\section{METHODS}

- RJB32 method are Table 2 and Table 3 are encryption and decryption.

\section{ENCRYPTION}

- A is a data analyzed matrix. [10]

$$
\operatorname{En} A=\left(\begin{array}{lll}
102 & 103 & 104 \\
106 & 105 & 105 \\
108 & 110 & 102
\end{array}\right)
$$

$\mathrm{Se}=1 / 3$

Equation (1)"

"Pair-1(8,10)"

$$
\operatorname{En} A=\left(\begin{array}{lll}
102 / 3 & 103 / 3 & 104 / 3 \\
106 / 3 & 105 / 3 & 105 / 3 \\
108 / 3 & 110 / 3 & 102 / 3
\end{array}\right)
$$

$$
\operatorname{En} A=\left(\begin{array}{lll}
110 / 3 & 103 / 3 & 104 / 3 \\
106 / 3 & 105 / 3 & 105 / 3 \\
108 / 3 & 102 / 3 & 102 / 3
\end{array}\right)
$$

TABLE 2. RJB32 Encryption

\begin{tabular}{|c|l|}
\hline STEPS & \multicolumn{1}{|c|}{ RJB32 ENCRYPTION } \\
\hline 1 & Analyzed the prediction data from social media. \\
\hline 2 & Convert the prediction data to matrix A. \\
\hline 3 & $\begin{array}{l}\text { EnA }=\mathrm{Se} \text { A (1) } \\
\text { where EnA is encryption matrix A. }\end{array}$ \\
\hline 4 & Applying the prime numbers ES and ET. \\
\hline 5 & Calculate the $E S^{2}$ and $E T^{2}$. \\
\hline 6 & $E A 1=E S^{2}-E T^{2}(\mathbf{2})$ \\
\hline 7 & $E B 1=E S^{2}+E T^{2} \mathbf{( 3 )}$ \\
\hline
\end{tabular}




\begin{tabular}{|c|l|}
\hline 8 & $\begin{array}{l}\text { If EA1 and EB1 value will be above size of the matrix then add } \\
\text { and make it single digit values }\end{array}$ \\
\hline 9 & Swap EA1 and EB1 in EnA \\
\hline 10 & $\begin{array}{l}C A=C_{i}<->\left(C_{i+(n-m)}\right)(4) \text { where CA is Column encrypted matrix, } \\
\mathrm{C} \text { is a columns, } \mathrm{i}, \mathrm{n} \text { and } \mathrm{m} \text { is column numbers }\end{array}$ \\
\hline
\end{tabular}

"Pair-2(24,26)"

$$
\operatorname{En} A=\left(\begin{array}{lll}
110 / 3 & 103 / 3 & 104 / 3 \\
106 / 3 & 105 / 3 & 102 / 3 \\
108 / 3 & 105 / 3 & 102 / 3
\end{array}\right)
$$

"Pair-3(40,58)"

$$
E n A=\left(\begin{array}{lll}
110 / 3 & 103 / 3 & 104 / 3 \\
106 / 3 & 105 / 3 & 102 / 3 \\
108 / 3 & 105 / 3 & 102 / 3
\end{array}\right)
$$

"Pair-4(72,90)"

$$
\mathrm{EnA}=\left(\begin{array}{lll}
110 / 3 & 103 / 3 & 104 / 3 \\
106 / 3 & 105 / 3 & 102 / 3 \\
108 / 3 & 105 / 3 & 102 / 3
\end{array}\right)
$$

Equation(4)

$$
C A=\left(\begin{array}{lll}
104 / 3 & 103 / 3 & 110 / 3 \\
102 / 3 & 105 / 3 & 106 / 3 \\
102 / 3 & 105 / 3 & 108 / 3
\end{array}\right)
$$

\section{DECRYPTION}

$$
\operatorname{Dn} A=\left(\begin{array}{lll}
104 / 3 & 103 / 3 & 110 / 3 \\
102 / 3 & 105 / 3 & 106 / 3 \\
102 / 3 & 105 / 3 & 108 / 3
\end{array}\right)
$$

TABLE 3. RBJ32 Decryption

\begin{tabular}{|c|l|}
\hline STEPS & \multicolumn{1}{|c|}{ RJB32 DECRYPTION } \\
\hline 1 & $\begin{array}{l}D A=D_{i}<->\left(D_{i+(n-m)}\right)(\mathbf{5}) \text { where CA is Column encrypted matrix, } \\
\text { C is a columns, } \mathrm{i}, \mathrm{n} \text { and } \mathrm{m} \text { is column numbers }\end{array}$ \\
\hline 2 & Applying the prime numbers DS and DT. \\
\hline 3 & Calculate the $D S^{2}$ and $D T^{2}$. \\
\hline 4 & $D A 1=D S^{2}-D T^{2}(\mathbf{6})$ \\
\hline 5 & $D B 1=D S^{2}+D T^{2} \mathbf{( 7 )}$ \\
\hline 6 & Swap A1 and B1 \\
\hline
\end{tabular}




\section{Equation(5)}

$$
\operatorname{Dn} A=\left(\begin{array}{lll}
110 / 3 & 103 / 3 & 104 / 3 \\
106 / 3 & 105 / 3 & 102 / 3 \\
108 / 3 & 105 / 3 & 102 / 3
\end{array}\right)
$$

"Pair-1(90,72)"

$$
\operatorname{Dn} A=\left(\begin{array}{lll}
110 / 3 & 103 / 3 & 104 / 3 \\
106 / 3 & 105 / 3 & 102 / 3 \\
108 / 3 & 105 / 3 & 102 / 3
\end{array}\right)
$$

"Pair-2(58,40)"

$$
\operatorname{Dn} A=\left(\begin{array}{lll}
110 / 3 & 103 / 3 & 104 / 3 \\
106 / 3 & 105 / 3 & 102 / 3 \\
108 / 3 & 105 / 3 & 102 / 3
\end{array}\right)
$$

"Pair-3(26,24)"

$$
\operatorname{DnA}=\left(\begin{array}{lll}
110 / 3 & 103 / 3 & 104 / 3 \\
106 / 3 & 105 / 3 & 105 / 3 \\
108 / 3 & 102 / 3 & 102 / 3
\end{array}\right)
$$

Pair-4(10, 8)"

$$
\operatorname{Dn} A=\left(\begin{array}{lll}
102 / 3 & 103 / 3 & 104 / 3 \\
106 / 3 & 105 / 3 & 105 / 3 \\
108 / 3 & 110 / 3 & 102 / 3
\end{array}\right)
$$

"Equation (8)"

$$
\operatorname{En} A=\left(\begin{array}{lll}
102 & 103 & 104 \\
106 & 105 & 105 \\
108 & 110 & 102
\end{array}\right)
$$

\section{CONCLUSION}

The present world is data world; without this data cannot survive in present stage. This data produced more from social media; this media data is public data; This public data not have good security; so to overcome this issue we apply the Salsa method. This method easily hack the data from the hackers. RBJ32 method has 5 
steps. 1. Applying the key and multiply that key; 2 . To apply the prime number in the $S^{2}$ and $T^{2} ; 3$. To calculate the EA1 and EA2; 4. To swap the EA1 and EA2 in matrix EnA; 5. Apply the column operations. The RJB32 method provide good security while compared with Salsa method. In the future, to add the prime factors operations of the data security.

\section{REFERENCES}

[1] P. A. BABU AND J. J. THOMAS: A Practical Fault Attack on ARX-like Ciphers with a Case Study on ChaCha20, Wo. on Fa. Di. and To. in Cr. (2017), 33-40.

[2] S. V. D. KUMAR, S. PATRANABIS, J. BREIER, D. MUKHOPADHYAY, S. BHASIN, A. CHATTOPADHYAY, AND A. BAKS: Freestyle, a randomized version of ChaCha for resisting offline brute-force and dictionary attacks, IE. tr. on In. Fo. and Se. (2018).

[3] A. ADOMNICAI, J. J. A. FOURNIER, AND L. MASSON: Bricklayer Attack: A Side- Channel Analysis on the ChaCha Quarter Round, Pr. in Cr. In., Le. No. in Co. Sc., Sp. 65-84.

[4] B. MAZUMDAR, S.K. S. ALI AND O. SINANOGLU: Power Analysis Attacks on ARX: An Application to Salsa20, On-. Te. Sy. IE. (2015), 4043.

[5] C. WATT, J. RENNER, N. POPESCU, S. CAULIGI, AND D. STEFAN: CT-Wasm: Type- Driven Secure Cryptography for The Web Ecosystem, Pr. ACM Pr. La. PO. (2019), 77:1-77:29.

[6] C. BAGATH BASHA, S. RAJAPRAKASH: Enhancing The Security Using SRB18 Method of Embedding Computing, Mic. and Mic 103125, (2020).

[7] C. B. BASHA, S. RAJAPRAKASH: Securing Twitter Data Using Srb21 Phase I Methodology, Int. Jou. of Sci. and Tec. Res. 8(12) (2019), 19521955.

[8] C. B. BASHA, S. RAJAPRAKASH: Applying The CBB21 Phase 2 Method For Securing Twitter Analyzed Data, Adv. In Mat. : Sci. Jou. 9(3) (2020), 1085-1091.

[9] C. B. BASHA, S. RAJAPRAKASH, V. V. A. HARISH, M. S. KRISHNA, K. PRABHAS: Securing Twitter Analysed Data Using CBB22 Algorithm, Adv. In Mat. : Sci. Jou. 9(3) (2020), 1093-1100.

[10] C. B. BASHA, K. SOMASUNDARAM: A Comparative Study of Twitter Sentiment Analysis Using Machine Learning Algorithms in Big Data, Int. Jou. of Rec. Tec. and Eng. 8(1) (2019), 591-599.

[11] Somasekar, J. \& Sharma, A. \& Reddy, N. \& Reddy, Y.. (2020). IMAGE ANALYSIS FOR AUTOMATIC ENUMERATION OF RBC INFECTED WITH PLASMODIUM PARASITES-IMPLICATIONS FOR MALARIA DIAGNOSIS. Advances in Mathematics: Scientific Journal. 9. 1221-1230. 10.37418/amsj.9.3.48. 
[12] A. SHARMA1 AND J. SOMASEKAR "Contrast Image Construction Technique for Medical Imaging" published in Advances in Mathematics: Scientific Journal (Adv. Math., Sci. J.) vol-9-no-6-2020 (pp 3325-3329)

[13] Rohini Goel, Avinash Sharma, and Rajiv Kapoor, "Object Recognition Using Deep Learning" published in Journal of Computational and Theoretical Nanoscience Vol. 16, 4044-4052, 2019

[14] Santosh, Mamta \& Sharma, Avinash. (2019). A Proposed Framework for Emotion Recognition Using Canberra Distance Classifier. Journal of Computational and Theoretical Nanoscience. 16. 3778-3782. 10.1166/jctn.2019.8250.

[15] Mamta Santosh, Avinash Sharma, "Facial Expression Recognition using Fusion of LBP and HoG Features" published in International Journal of Innovative Technology and Exploring Engineering (IJITEE) ISSN: 2278-3075, Volume-8 Issue-8 June, 2019 